\title{
Development of an electrochemical RNA-aptasensor to detect human osteopontin
}

\author{
Sofia G. Meirinho a,*, Luís G. Dias ${ }^{\mathrm{b}, \mathrm{c}}$, António M. Peres ${ }^{\mathrm{d}}$, Lígia R. Rodrigues ${ }^{\mathrm{a}}$ \\ ${ }^{a}$ Centre of Biological Engineering (CEB), University of Minho, Campus de Gualtar, 4710-057 Braga, Portugal \\ ${ }^{\mathrm{b}}$ ESA, Instituto Politécnico de Bragança, Campus Santa Apolónia, Apartado 1172, 5301-855 Bragança, Portugal \\ c CQ-VR, Centro de Química - Vila Real, University of Trás-os-Montes e Alto Douro, Apartado 1013, 5001-801 Vila Real, Portugal \\ ${ }^{\mathrm{d}}$ LSRE-Laboratory of Separation and Reaction Enginerring-Associate Laboratory LSRE/LCM, ESA, Instituto Politécnico de Bragança, Campus Santa Apolónia, \\ Apartado 1172, 5301-855 Bragança, Portugal
}

\section{A R T I C L E I N F O}

\section{Article history:}

Received 26 January 2015

Received in revised form

30 March 2015

Accepted 17 April 2015

Available online 20 April 2015

Keywords:

RNA aptamer

Voltammetric aptasensor

Osteopontin

Protein biomarker.

\begin{abstract}
A B S T R A C T
Electrochemical aptasensors may be used to detect protein biomarkers related to tumor activity. Osteopontin (OPN), a protein present in several body fluids, has been suggested as a potential biomarker since its overexpression seems to be associated with breast cancer progression and metastasis. In this work, a simple and label-free voltammetric aptasensor for the detection of OPN, using an RNA aptamer previously reported to have affinity for human OPN as the molecular recognition element, and the ferro/ ferricyanide solution as a redox probe, was developed. The RNA aptamer was synthetized and immobilized in a working microelectrode gold surface (diameter of $0.8 \mathrm{~mm}$ ) of a screen-printed strip with a silver pseudo-reference electrode and a gold counter electrode. The electrochemical behavior of the electrode surface after each preparation step of the aptasensor was studied using cyclic voltammetry and square wave voltammetry. The resulting voltammetric aptasensor was used to detect OPN in standard solutions. Cyclic voltammetry results showed that the aptasensor has reasonable detection and quantification limits $(3.7 \pm 0.6 \mathrm{nM}$ and $11 \pm 2 \mathrm{nM}$, respectively). Indeed, the detection limit falls within the osteopontin levels reported in the literature for patients with metastatic breast cancer. Moreover, the aptasensor is able to selectively detect the target protein in the presence of other interfering proteins, except for thrombin. Considering the overall results, a possible application of the aptasensor for cancer prognosis may be foreseen in a near future.
\end{abstract}

(c) 2015 Elsevier B.V. All rights reserved.

\section{Introduction}

Breast cancer is a major cause of mortality among women worldwide. According to the International Agency of Research on Cancer (IARC) and World Health Organization (WHO), in 2012, 1.67 million women were diagnosed with breast cancer, the second most common cancer in women and the fifth leading cause of death (522,000 deaths) (Ferlay et al., 2013). Breast cancer is a complex disease with a very heterogeneous clinical nature, for which it is crucial to identify new biomarkers associated with tumor growth, angiogenesis and metastasis (Thorat et al., 2013). Osteopontin (OPN) is a multifunctional phosphorylated glycoprotein, expressed as a 41-75 kDa protein due to varied post-translational modifications (Anborgh et al., 2011; Tuck et al., 2007; Wai and Kuo, 2008). OPN can be found in all body fluids and is

\footnotetext{
* Correspondence to: University of Minho, Campus de Gualtar, 4710-057 Braga, Portugal. Fax: +351 253604429.

E-mail address: smeirinho@deb.uminho.pt (S.G. Meirinho).
}

considered as a potential serum tumor marker (Macrì et al., 2009; Rodrigues et al., 2007; Tuck et al., 2007; Weber et al., 2011, 2010), a possible therapeutic target for blocking tumor growth and subsequent metastasis, as well as a cancer regulator (Mi et al., 2009a; Rodrigues et al., 2009). Recent studies demonstrated that circulating levels of OPN contribute to the tumor formation and aggressiveness, progression and metastasis (Ahmed and Kundu, 2010; Bache et al., 2010; Bramwell et al., 2014; Mirza et al., 2008; Rodrigues et al., 2007). Increased OPN protein levels in serum or tumor have been associated with several clinical parameters, such as tumor stage, tumor grade, tumor subtype, tumor size and the time of relapse (Bache et al., 2010). In breast cancer, a high OPN expression, measured both in plasma and tumor tissue, has been associated with a decreased survival (Bramwell et al., 2006), as well as poor prognosis and disease progression (Rudland et al., 2002; Weber et al., 2010). In 2014, Bramwell et al. (2014) were able to measure, using enzyme-linked immunosorbent assay (ELISA) the OPN levels in plasma samples of patients with metastatic breast cancer. The results showed that plasma OPN concentrations in patients with metastatic breast cancer were on average $46 \mathrm{ng} /$ 
$\mathrm{ml}$ (ranging from 22.6 to $290 \mathrm{ng} / \mathrm{ml}$ ).

Nowadays, traditional methodologies, such as mammography and ELISA, are used for early detection of breast cancer and detection of OPN in plasma, respectively. However, these techniques present some limitations, thus it is of utmost relevance to develop new non-invasive methods for the detection of tumor markers detection, as for example the detection of OPN in body fluids. These non-invasive methods would allow following the patients' treatment or facilitate the detection of breast cancer in an early stage of the disease, thus enabling an increased success of cancer treatments. Electrochemical aptasensors may be a suitable alternative to the above mentioned diagnosis methods. Technically, aptasensors can be fabricated to respond to any target molecule for which an aptamer can be generated. Several electrochemical aptasensors have been reported for the specific detection of biomarker proteins in body fluids, such as thrombin (Xiao et al., 2005a, 2005b), C-reactive protein (Centi et al., 2009) and plateletderived growth factor (PDGF) (Lai et al., 2007). Electrochemical detection has attracted considerable attention in the development of aptasensors since it exhibits high sensitivity, simple instrumentation, low production cost, fast response, and portability (Arshak et al., 2009; Radi, 2011; Saberian et al., 2011; Song et al., 2008; Velasco-Garcia and Missailidis, 2009; Velusamy et al., 2010; Xu et al., 2009). On the other hand, aptamers are short singlestranded DNA or RNA oligonucleotides with high affinity and specificity for a specific protein, which can be obtained using a selection process, namely the systematic evolution of ligands by exponential enrichment (SELEX). The dissociations constants of aptamer-target complexes typically range from the low micromolar to high picomolar levels (Jing et al., 2011). The potential use of aptamers in clinical applications implies understanding the aptamer-protein interactions. In the literature, several methods for dissociations constants determination have been described including dialysis, ultrafiltration, electrophoretic mobility shift gel, affinity capillary electrophoresis, fluorescence intensity and anisotropy, UV-vis absorption and circular dichroism, surface plasmon resonance and isothermal titration calorimetry (Jing et al., 2011; Tran et al., 2010). Aptamers are easy to synthesize and chemically modify, possessing high sensitivity and selectivity towards the target, good stability in complex environments and resistance to denaturation and degradation. Therefore, aptamers are ideal biological recognition elements for the development of biosensors, especially if compared with antibody-based strategies (Hianik and Wang, 2009; Radi, 2011; Song et al., 2012; Strehlitz et al., 2008). Recently, Mi et al. (2009b) isolated an RNA aptamer against human OPN (dissociation constant $\left(K_{d}\right)$ of $18 \mathrm{nM}$ ) using SELEX, which could be further explored in the development of an electrochemical biosensor to detect OPN. Indeed, more recently, Cao et al. (2014), proposed an electrochemical aptasensor method for the detection of human OPN using the square wave voltammetry (SWV) technique with a pyrolytic graphite disk electrode (3.0 mm diameter), functionalized with gold nanoparticles in synthetic host macromolecule substrate, and the same RNA-aptamer (Mi et al., 2009b). This electrochemical method allowed detecting human OPN with a detection limit of $10.7 \mathrm{ng} / \mathrm{mL}$ (Cao et al., 2014). However, the application of nanomaterials increase the cost of the biosensor and, in complex samples, its reproducibility and quantification may be affected (Yu et al., 2012). On the other hand, Chen et al. (2014), developed an electrochemical immunosensor for human OPN detection through the impedance spectroscopy technique, which had a detection limit of $0.17 \mathrm{nM}$. Though, as mentioned above, aptamers present some advantages over immunological compounds, and the number of applications involving their use greatly increased in the recent years.

In this work, a simple electrochemical aptasensor for the detection of human OPN was developed based in a preliminary study of our research group (Meirinho et al., 2014). For that purpose, the RNA aptamer previously described by Mi et al. (2009b) was studied in its aptamer-rhOPN binding affinity using fluorescence assays and as an aptasensor through its immobilization in a screen printed gold electrode (SPGE) by streptavidin-biotin interaction. Cyclic voltammetry $(\mathrm{CV})$, with a $\left[\mathrm{Fe}(\mathrm{CN})_{6}\right]^{3-/ 4-}$ redox probe, was used to evaluate the biosensor performance towards human OPN detection, as well as the influence of other interfering proteins. As a complementary technique, square wave voltammetry (SWV) was also applied to follow the steps of the aptasensor construction, enabling a comparison between the observed electrochemical behaviors after each step.

\section{Experimental}

\subsection{Material and reagents}

Recombinant human osteopontin (rhOPN, $65 \mathrm{kDa}$ ) and recombinant bovine osteopontin (rbOPN, $60 \mathrm{kDa}$ ) were purchased from R\&D Systems. Thrombin from human plasma (THR, $37.4 \mathrm{kDa}$ ), Bovine serum albumin (BSA, $66 \mathrm{kDa}$ ), lysozyme from chicken egg white (LYS, $14.3 \mathrm{kDa}$ ) and streptavidin were obtained from SigmaAldrich. All proteins were acquired lyophilized and manipulated according to the manufacturers' specifications. Diethypyrocarbonate (DEPC), 3,3-dithiodipropionic acid (DPA), N-(3-dimethylaminopropyl)-N-ethylcarbodiimide hydrochloride (EDC), N-hydroxysuccinimide (NHS), ethanolamine (ETA) and sulfuric acid (purity of 99.999\%) were obtained from Sigma-Aldrich. Potassium hexacyanoferrate (III) $\left(\mathrm{K}_{3} \mathrm{Fe}(\mathrm{CN})_{6}\right)$ and potassium hexacyanoferrate (II) $\left(\mathrm{K}_{4} \mathrm{Fe}(\mathrm{CN})_{6}\right)$ were obtained from Acros Organics and potassium dihydrogen phosphate $\left(\mathrm{KH}_{2} \mathrm{PO}_{4}\right)$ from Merck. Sodium chloride $(\mathrm{NaCl})$, potassium chloride $(\mathrm{KCl})$ and sodium hydrogen phosphate $\left(\mathrm{Na}_{2} \mathrm{HPO}_{4}\right)$ were acquired from Panreac. All chemicals were of analytical grade and used as received. Deionized water (18.2 M $\Omega$ ) purified by a milli-QTM system (Millipore) was used throughout the experiment for aqueous solutions preparation.

Phosphate buffer saline (PBS) solution (137 mM NaCl, $2.7 \mathrm{mM}$ $\mathrm{KCl}, 8.1 \mathrm{mM} \mathrm{Na}_{2} \mathrm{HPO}_{4}$ and $1.47 \mathrm{mM} \mathrm{KH}_{2} \mathrm{PO}_{4}$ ) with an adjusted $\mathrm{pH}$ of 7.4 was used. The ferro/ferricyanide redox probe $(5 \mathrm{mM}$ $\mathrm{K}_{3} \mathrm{Fe}(\mathrm{CN})_{6}$ and $\mathrm{K}_{4} \mathrm{Fe}(\mathrm{CN})_{6}(1: 1)$, and $10 \mathrm{mMKCl}$ in $100 \mathrm{~mL}$ of PBS), with an adjusted $\mathrm{pH}$ of 7.4 , was daily prepared.

Stock solutions of $200 \mathrm{mM}$ EDC, $100 \mathrm{mM}$ NHS, as well as the stock solution $1 \mathrm{mg} / \mathrm{ml}$ of septravidin in PBS ( $\mathrm{pH} 7.4$ ) were stored at $-20{ }^{\circ} \mathrm{C}$ before use. Stock solutions of $200 \mathrm{nM}$ DPA and $100 \mathrm{mM}$ of ethanolamine (ETA) were stored at $4{ }^{\circ} \mathrm{C}$. Stock solutions of each protein were prepared according to the manufacturer specifications and stored at $-20^{\circ} \mathrm{C}$. The protein working solutions were obtained by dilution with PBS buffer ( $\mathrm{pH} 7.4)$ and stored at $4{ }^{\circ} \mathrm{C}$ until use.

\subsubsection{RNA aptamer}

The RNA aptamer herein used was reported by Mi et al. (2009a). The sequence of the biotinylated RNA aptamer (5'-BiotinCGGCCACAGAAUGAAAAACCUCAUCGAUGUUGCAUAGUUG-3') was synthesized by Integrated DNA Technologies (Belgium).

Stock solutions $(100 \mu \mathrm{M})$ of the synthetic oligonucleotides were prepared with ultra-pure water containing $1 \%$ DEPC (v/v) to avoid the RNase interference. The working RNA aptamer solution was prepared by dilution using fresh PBS. Before the RNA aptamer immobilization on the gold working electrode, the biotinylated RNA aptamer prepared in PBS buffer ( $\mathrm{pH} 7.4$ ) was subjected to a temperature treatment $\left(95^{\circ} \mathrm{C}\right.$ during $5 \mathrm{~min}, 4^{\circ} \mathrm{C}$ for $5 \mathrm{~min}$ and $10 \mathrm{~min}$ at room temperature) in order to obtain an adequate structure flexibility of the aptamer for the interaction with 
streptavidin on the gold electrode surface.

\subsection{Apparatus}

Electrochemical analyzes were performed at room temperature using a Potentiostat-Galvanostat device (PG580, Uniscan Instruments). The screen-printed gold electrodes (SPGEs) (DropSens, S. L., Spain) has a gold working electrode with a diameter of $0.8 \mathrm{~mm}$, as well as a silver pseudo-reference electrode and a gold counter electrode. The $\mathrm{pH}$ was measured using a $\mathrm{pH}$ meter (iHANNA instruments $\mathrm{pH}$ 211). The fluorescence measurements were performed in 96-dark-well plates using an ELISA reader (Synergy HT, BIO-TEK, IZASA) equipped with thermostat holding a temperature control accuracy of $0.1{ }^{\circ} \mathrm{C}$ and configured with $492 \mathrm{~nm}$ excitation and $518 \mathrm{~nm}$ emission filters. The Gen $5^{\mathrm{TM}}$ data analysis software was used for collecting microplate data and conducting the analysis after settle a range of excitation and emission wavelengths.

\subsection{Fluorescent aptamer-protein binding affinity assays}

Fluorescence assays were performed to evaluate the binding affinity of the RNA aptamer towards rhOPN. For that purpose, a fluorophore 6-carboxyfluorescein (FAM) was attached to the 5'end of the RNA aptamer sequence (i.e., 5'-FAM-CGGCCACAGAAUGAAAAACCUCAUCGAUGUUGCAUAGUUG-3'), which was supplied by Alfagene (Portugal). Before each fluorescence assay, the FAMRNA aptamer was heated at $95{ }^{\circ} \mathrm{C}$ during $5 \mathrm{~min}$, then cooled at $4{ }^{\circ} \mathrm{C}$ for $5 \mathrm{~min}$ and finally $10 \mathrm{~min}$ at room temperature to facilitate the folding of the aptamer.

First, the fluorescence of the FAM-RNA aptamer was studied. FAM-RNA aptamer solutions with concentrations varying from 2.5 to $100 \mathrm{nM}$ were prepared and the related fluorescence intensity of the free aptamer (non-bound to any protein) was measured. The different solutions of FAM-RNA aptamer were incubated for $30 \mathrm{~min}$ and $4 \mathrm{~h}$ at room temperature. After this, the solutions were excited at $492 \mathrm{~nm}$ and fluorescence was measured at $518 \mathrm{~nm}$. Based on these assays, calibration curves relating the fluorescence intensity and FAM-RNA aptamer concentrations were established for both incubation times ( $30 \mathrm{~min}$ and $4 \mathrm{~h}$ ), enabling the evaluation of the fluorescence contribution of the free aptamer and, if necessary, the estimation of the free aptamer concentration for the binding aptamer-protein studies.

Regarding the aptamer-protein complex formation, a $20 \mathrm{nM}$ FAM-RNA aptamer solution was prepared in PBS buffer at pH 7.6. For each fluorescence assay, $60 \mu \mathrm{L}$ of a $20 \mathrm{nM}$ solution of RNA aptamer modified with FAM-RNA-aptamer, were incubated with the same volume of different concentrations of rhOPN $(0,3,10$, $100,300,370 \mathrm{nM}$ ) prepared in the same buffer (Potty et al., 2009; Tran et al., 2010), in 96-dark-well plates. The mixtures were incubated at room temperature for two different periods, i.e. 30 min and $4 \mathrm{~h}$. The mixture was excited at $492 \mathrm{~nm}$ and fluorescence was measured at $518 \mathrm{~nm}$.

Since THR is a protein present in the human blood and could act as an interferent during the electrochemical analysis of blood samples, these same experiments were also conducted for THR. Indeed, rhOPN contains a THR cleavage domain, thus the RNA aptamer could hold a site that may also recognize THR.

\subsection{Aptamer-protein binding affinity parameter}

Fluorescence data were further used to determine the dissociation constant $\left(K_{d}\right)$, which is the reciprocal of the binding pseudo-equilibrium constant of the aptamer-protein complex formation. A one-to-one binding aptamer-protein stoichiometry was assumed (i.e. identical and equivalent binding sites for protein and aptamer), thus it was supposed that one mole of protein could only bind to one mole of aptamer.

Briefly, the aptamer-protein complex $(P-A P T)$ formation may be represented by the equation proposed by Jing et al. (2011)

$P+A P T \leftrightarrow P-A P T$

being $P$ and $A P T$ the protein and aptamer, respectively.

In this case, the dissociation constant could be calculated by

$K_{d}=\frac{[P][A P T]}{[P-A P T]}$

where $[P]$ and $[A P T]$ are the concentrations of free protein and free aptamer, i.e. non-bound, respectively.

Including the fraction of bound aptamer $\left(f_{A P T}\right)$, as the ratio between the concentrations of bound aptamer and the total aptamer (for assays with constant initial aptamer concentration and increasing protein concentrations, i.e. when RNA aptamer is titrated with a broad concentration range of protein), the following equation can be established:

$f_{A P T}=\frac{[A P T]_{\text {bound }}}{[A P T]_{\text {initial }}}=\frac{[P-A P T]}{[P-A P T]+[A P T]}$

Considering one-to-one equilibrium, $[A P T]_{\text {bound }}=[\mathrm{P}-\mathrm{APT}]$ and $[A P T]_{\text {initial }}=[A P T]_{\text {bound }}+[A P T]$ can be assumed.

Afterwards, replacing $[P-A P T]$ in Eq. (3) with the result of the Eq. (2) the following relation can be derived:

$f_{A P T}=\frac{[P]}{K_{d}+[P]}$

and after rearranging

$\frac{f_{A P T}}{[P]}=\frac{1}{K_{d}}-\frac{f_{A P T}}{K_{d}}$

Eq. (5) is often known as the Scatchard equation and a straight line with a slope equal to $-\frac{1}{K_{d}}$ will be obtained by plotting $\frac{f_{A P T}}{[P]}$ versus $f_{\text {APT }}$. This procedure allows a straightforward calculation of the $K_{a}$ value and to infer about the binding affinity between the aptamer and the protein. Alternatively, $K_{G}$ can be calculated using non-linear optimization algorithms using Eq. (4). In both cases, it is necessary to estimate $f_{A P T}$ experimentally and the concentration of free protein $([P])$ after each protein addition, assuming that the pseudo-equilibrium described by Eq. (1) is attained.

Some points must be considered, namely if the initial aptamer concentration is significantly smaller than $K_{a}$ (i.e., $[A P T]_{\text {initial }} K_{\mathrm{a}}$ ), the free protein concentration $[P]$ at equilibrium does not change significantly from the total protein concentration added, $[P]_{1}$ upon binding (i.e. $[P] \approx[P]_{t}$ ) and so Eq. (8) could be simplified to the one proposed by Jing et al. (2011)

$\frac{f_{A P T}}{[P]_{t}}=\frac{1}{K_{d}}-\frac{f_{A P T}}{K_{d}}$

(i) It is recommended to use data across the binding fraction range (i.e. $f_{A P T}$ values) of $0.2-0.8$ (Jing et al., 2011).

(ii) The values of $f_{A P T}$ must be calculated using Eq. (3) based on the concentration of bound aptamer ([APT bound $]$ ) estimated using the experimental fluorescence data.

Hence, to estimate $[A P T]_{\text {bounc }}$ the following procedure could be implemented. If both the aptamer non-bound and the aptamerprotein complex formed ( $F_{A P T}$ and $F_{P-A P T}$, respectively) exhibit fluorescence, then the total fluorescence measured $\left(F_{l}\right)$ would result from:

$F_{t}=F_{A P T}+F_{P-A P T}$ 
where, $F_{A P T}$ could be calculated using the regression parameter (intercept $a$ and slope $b$ ) of the calibration curve obtained by measuring the fluorescence of increasing aptamer concentration solutions without the presence of the protein,

$F_{A P T}=a+b[A P T]$

and $\mathrm{F}_{P-A P T}$ may be estimated assuming a proportionality coefficient between fluorescence intensity and the complex concentration, $[P-A P T]$, like

$F_{P-A P T}=c[P-A P T]$

being the coefficient $c$ estimated based on the constant maximum fluorescence intensity observed in the titration curve (increasing protein concentrations added to a fixed initial aptamer concentration), a situation where all the initial APT is bound to $P$ (no free APT is available in the solution), thus all measured fluorescence would be due to the $P-A P T$ complex, which concentration, for a one-to-one binding stoichiometry, could be assumed as:

$[P-A P T]=[A P T]_{\text {initial }}$

and so,

$c=\frac{F_{t, \text { maximum }}}{[A P T]_{\text {initial }}}$

Replacing Eqs. (8)-(11) into the Eq. (7), and by using the relations between the concentrations of protein and aptamer, bound or free, it is possible to obtain an explicit equation for $[A P T]_{\text {bound }}$ :

$F_{t}=a+b[A P T]+\frac{F_{t, \text { maximum }}}{[A P T]_{\text {initial }}}[P-A P T]$

$F_{t}=a+b\left([A P T]_{\text {initial }}-[A P T]_{\text {bound }}\right)+\frac{F_{t, \text { maximum }}}{[A P T]_{\text {initial }}}[A P T]_{\text {bound }}$

$[A P T]_{\text {bound }}=\frac{F_{t}-a-b[A P T]_{\text {initial }}}{\frac{F_{t, \text { maximum }}}{[A P T]_{\text {initial }}}-b}$

Finally, Eq. (3) could be modified to enable the direct calculation of $f_{A P T}$ from experimental fluorescence data:

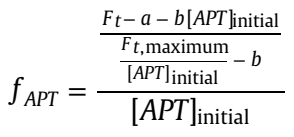

When the RNA-aptamer concentration approaches or is greater than $K_{a}\left([A P T]_{\text {initial }} \geq K_{a}\right)$, this parameter should not be calculated using Eq. (6) since $[P]$ cannot be considered equal to $[P]_{t}$ and so, in Eq. (6) the free protein concentration should be replaced by:

$[P]=[P]_{t}-[P]_{\text {bound }}=[P]_{t}-[P-A P T]$

Similarly,

$[A P T]=[A P T]_{\text {initial }}-[A P T]_{\text {bound }}=[A P T]_{\text {initial }}-[P-A P T]$

Therefore, by making these replacements in Eq. (2) the following equation for the complex concentration may be derived, as described by Jing et al. (2011)

$[P]_{t}+[A P T]_{\text {initial }}+K_{d}$
$[P-A P T]=\frac{-\sqrt{\left([P]_{t}+[A P T]_{\text {initial }}+K_{d}\right)^{2}-4[P]_{t}[A P T]_{\text {initial }}}}{2}$

Finally, by replacing these equations in Eq. (4) an expression is obtained for the case where the initial aptamer concentration is not smaller than the dissociation constant:

$$
\begin{aligned}
& f_{A P T}= \\
& \quad \frac{[P]_{t}-\frac{[P]_{t}+[A P T]_{\text {initial }}+K_{d-} \sqrt{\left.\left([P]_{t}+[A P T]_{\text {initial }}+K_{d}\right)^{2}-4[P]_{t} A P P T\right]_{\text {initial }}}}{2}}{K_{d}+[P]_{t}-\frac{[P]_{t}+[A P T]_{\text {initial }}+K d-\sqrt{\left([P]_{t}+[A P T]_{\text {initial }}+K d\right)^{2}-4[P]_{t}[A P T]_{\text {initial }}}}{2}}
\end{aligned}
$$

Combining Eqs. (13) and (17) it is then possible to calculate $K_{a}$ value by applying a non-linear optimization algorithm.

In this study, $K_{a}$ values were estimated using the LevenbergMarquardt nonlinear least-squares minimization method. This optimization procedure uses the gradient descent and GaussNewton minimization algorithms, ensuring that a solution is found even if the starting values of the unknown terms are not close to those obtained in the final adjustment. The first algorithm is applied when the sum of squared deviations is large and, the second, when the optimal value is approached (Bloomfield, 2014). The Levenberg-Marquardt method was applied using the package minpack.lm Timur (2013) of the R software.

\subsection{RNA aptamer immobilization}

The electrochemical-based aptamer biosensor was obtained using a biotinylated RNA aptamer immobilized on a streptavidinmodified gold electrode surface (Fig. 2A).The substances, concentrations, temperatures and times used in the RNA aptamer immobilization steps were established based on data reported in the literature (Kim et al., 2010; Xiao et al., 2005a).

First, the working gold electrode surface was cleaned successively with three solutions $\left(0.5 \mathrm{M} \mathrm{H}_{2} \mathrm{SO}_{4}, 0.01 \mathrm{M} \mathrm{KCl} / 0.1 \mathrm{M} \mathrm{H}_{2} \mathrm{SO}_{4}\right.$ and $0.05 \mathrm{M} \mathrm{H}_{2} \mathrm{SO}_{4}$ ) under electric potential in the range of $-0.3-1.5 \mathrm{~V}$, and at scan rate of $100 \mathrm{mV} / \mathrm{s}$. An etching step, with $\left[\mathrm{Fe}(\mathrm{CN})_{6}\right]^{3-14-}$ solution, was carried out to ensure the homogeneity of the working gold surface. Afterwards, a self-assembled monolayer (SAM) was formed through an incubation step, using a $200 \mathrm{mM}$ solution of DPA (30 min at room temperature). The working electrode was then washed with ultra-pure water and treated with $100 \mathrm{mM}$ solution of EDC and $1 \mathrm{mM}$ solution of NHS (1:1 v/v, $60 \mathrm{~min}$ at room temperature) to activate the carboxyl groups, which facilitates the binding with the amino group of streptavidin during overnight incubation with streptavidin solution $\left(4^{\circ} \mathrm{C}\right)$. The working electrode was then exposed to ethanolamine ( $100 \mathrm{mM}, \mathrm{pH} 8.5$, during $20 \mathrm{~min}$ at room temperature) to block any remaining activated carboxyl groups. Finally, the biotinylated RNA aptamer was attached to the modified gold surface using the streptavidin-biotin interaction (40 min at room temperature) and the surface was rinsed thoroughly with PBS buffer ( $\mathrm{pH}$ 7.4) to remove the free aptamers. For the detection of rhOPN, a standard solution of protein in PBS ( $\mathrm{pH} 7.4$ ) was dropped $(\approx 5 \mu \mathrm{L}$ ) on the working electrode and incubated for $60 \mathrm{~min}$ at room temperature.After washing the electrode with PBS, to further remove non-binding rhOPN, $60 \mu \mathrm{L}$ of $\left[\mathrm{Fe}(\mathrm{CN})_{6}\right]^{3-14-}$ solution (redox probe) was dropped on the electrodes chip until all three electrodes were immersed. After this procedure CV assay was carried out to assess the level of RNA aptamer binding to the protein tested. All changes obtained in each preparation step of the aptasensor were followed by $\mathrm{CV}$ since it is a simple, rapid and sensitivity technique, which gives overall information regarding the reversibility of the oxidation and reduction mechanisms that occur at the electrode surface (Farghaly and Hameed, 2014). This electrochemical technique worked as a quality control tool and it allowed establishing typical redox probe cyclic voltammograms to monitor the effectiveness of the working electrode surface modification. If in any of the preparation steps, the 
cyclic voltammogram was not the expected, the sensor was discarded. SWV was also applied, for comparative purposes, to verify if the electrochemical behavior recorded after each preparation step during the aptasensor construction was similar for both techniques.

\subsection{Electrochemical measurements}

$\mathrm{CV}$ is widely used in electrochemical analysis to characterize electroactive compounds and electrode surfaces. This method involves linear forward and backward scanning within a fixed potential range, recorded at the working electrode, being the plot of the observed current versus the applied potential, the cyclic voltammogram. Anodic and cathodic peak current intensities and the respective potentials, at which these peaks are observed, provide valuable information regarding system reversibility and can be used to elucidate the oxidation/reduction mechanism at the electrode surface. Therefore, all electrodes used were evaluated and further characterized using $\mathrm{CV}$ and the electrochemical measurements were performed in the presence of $\left[\mathrm{Fe}(\mathrm{CN})_{6}\right]^{3-/ 4-}$ at room temperature. The $\mathrm{CV}$ measurements were performed under a potential range of $-0.5-0.6 \mathrm{~V}$ and at a scan rate of $50 \mathrm{mV} / \mathrm{s}$.

The current decrease (relative current change $(\Delta I \%)$ ) was calculated considering the current values of the cyclic voltammogram anodic peak recorded after aptamer immobilization and protein solution incubation by using the Eq. (18):

$\Delta I \%=\left(I_{0}-I_{1}\right) / I_{0} \times 100$

where $\Delta I$ is relative current change (\%); $I_{0}$ and $I_{1}$ represents the current before and after the sample incubation, respectively.

The detection limit (LOD) and quantification limit (LOQ) were calculated based on the linear relationship obtained between $\Delta I \%$ values of anodic peak current and different rhOPN concentrations. The detection limit and the quantification limits are calculated by the equations $\mathrm{LOD}=3(\mathrm{SD} / \mathrm{b})$ and $\mathrm{LOQ}=10(\mathrm{SD} / \mathrm{b})$, respectively, where SD is the standard deviation of the intercept and $b$ is the average slope of the regression line (Ermer and Miller, 2005).

SWV was also used since it is a fast and sensitive pulse method for which a symmetric square wave is superimposed on a staircase potential. The current is measured twice during each square wave cycle, at the end of the forward and reverse pulses, being the current difference plotted against the applied base potential. The SWV response is peak-shaped and the peak potential matches with the half-wave potential for a simple reversible ion transfer mechanism (Farghaly and Hameed, 2014). Under the CV optimized conditions, the SWV signal changes were observed for a potential range of $-0.5 \mathrm{~V}$ to $0.6 \mathrm{~V}$, at a frequency of $100 \mathrm{~Hz}$, an amplitude of $50 \mathrm{mV}$ and scan increment of $5 \mathrm{mV}$.

\section{Results and discussion}

\subsection{Evaluation of the aptamer-rhOPN binding affinity}

The aptamer-rhOPN binding evaluation was performed using fluorescence assays. First, fluorescence intensities were measured for increasing concentrations of FAM-RNA aptamer, enabling the establishment of two calibration curves for two incubation periods ( $30 \mathrm{~min}$ and $4 \mathrm{~h}$ ), as shown in Fig. 1A. Secondly, the aptamerrhOPN complex formation was followed by measuring the fluorescence intensity after the addition of different rhOPN concentrations to a solution with $20 \mathrm{nM}$ of FAM-RNA aptamer. The Fig. 1B shows the titration curve obtained for the two abovementioned incubation periods. This figure shows that total fluorescence increases with increasing rhOPN concentration, thus suggesting that the aptamer-protein complex exhibits fluorescence. Hence, the fluorescence intensity values measured result from the individual contribution of the non-bond aptamer and aptamer-rhOPN complex formed. These fluorescence data (Fig. 1A and $\mathrm{B}$ ) were used together with the equations described in Section 2.4 to verify the aptamer-rhOPN complex formation by means of $K_{d}$ estimation. Since for the RNA aptamer used in this work, a $K_{d}$ value of $18.0 \pm 0.2 \mathrm{nM}$ was already reported by Mi et al. (2009b), based in electrophoretic mobility shift assays, the $K_{d}$ values for the FAM-RNA aptamer were calculated using the mathematical procedure for $[\mathrm{APT}] \geq K_{d}$ (Eqs. (13) and (17)). Assuming only one aptamer-rhOPN high affinity-binding site, $K_{d}$ values of $1.6 \mathrm{nM}$ and $8.5 \mathrm{nM}$ were estimated for $30 \mathrm{~min}$ and $4 \mathrm{~h}$, respectively. These results pointed out that with an incubation of $30 \mathrm{~min}$ the binding site seems to have a higher affinity for rhOPN (lower $K_{d}$ value), showing that this time-period is sufficient to ensure the aptamerrhOPN binding.

\subsection{Electrochemical evaluation of the electrode surface}

The voltammetry assays were conducted to verify the electrochemical behavior of the electrode surface after each preparation step of the aptasensor. CV is a valuable and convenient tool to monitor the barrier of the modified electrode. This tool allows measuring electron transfer between the solution species and the electrode that must occur by tunneling either through the barrier
A

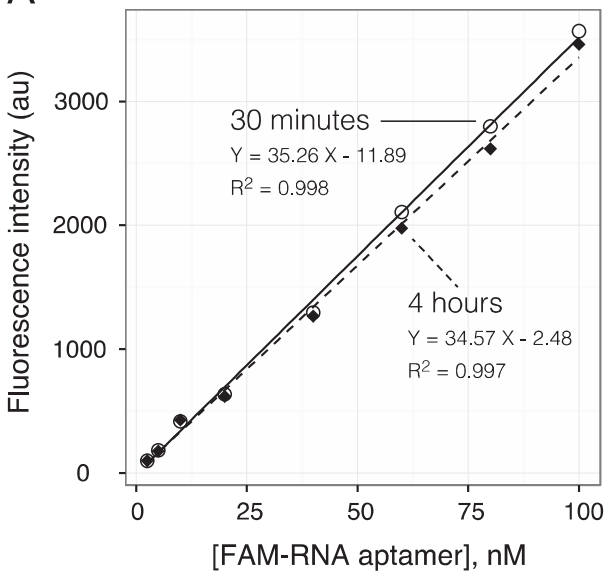

B

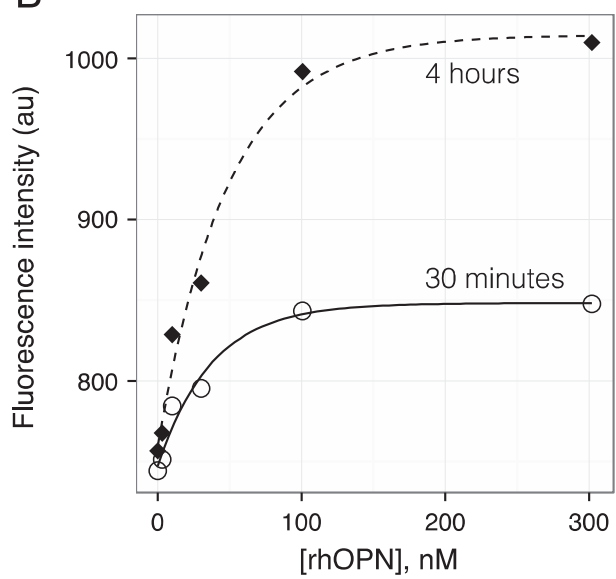

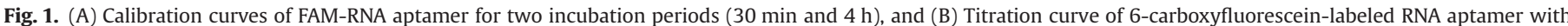
increasing rhOPN concentrations in PBS buffer pH 7.6 at $30 \mathrm{~min}$ and $4 \mathrm{~h}$ of incubation time. The concentration of RNA aptamer probe was fixed in 20 nM. 
or through the defects in the barrier (Olowu et al., 2011). The SWV is a more sensitive technique and was use to confirm the CV results in each step of the aptamer preparation. For these electrochemical studies, a $5 \mathrm{mM}$ solution of $\left[\mathrm{Fe}(\mathrm{CN})_{6}\right]^{3-/ 4-}$ was used as the redox probe.

Fig. 2 shows the various immobilization steps towards RNA aptamer onto a working gold electrode (Fig. 2A) and the sensor voltammograms obtained in each preparation steps using cyclic

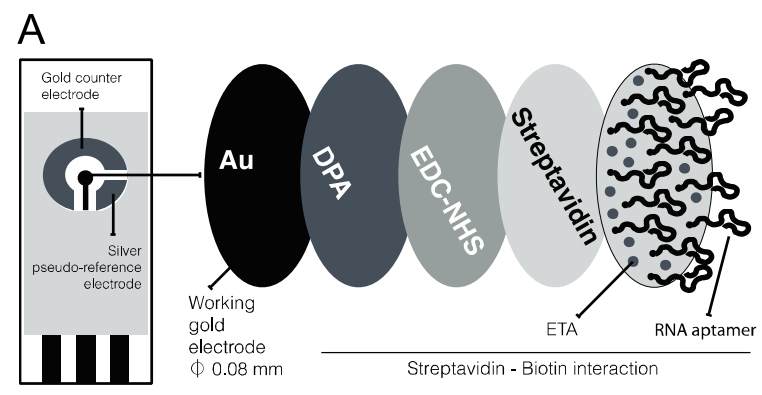

B1

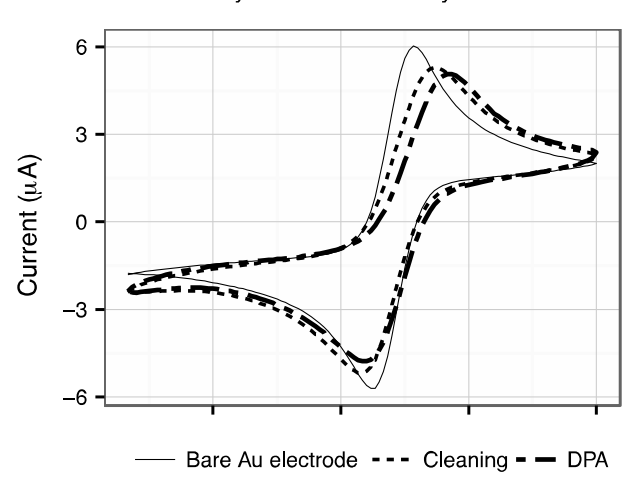

B2

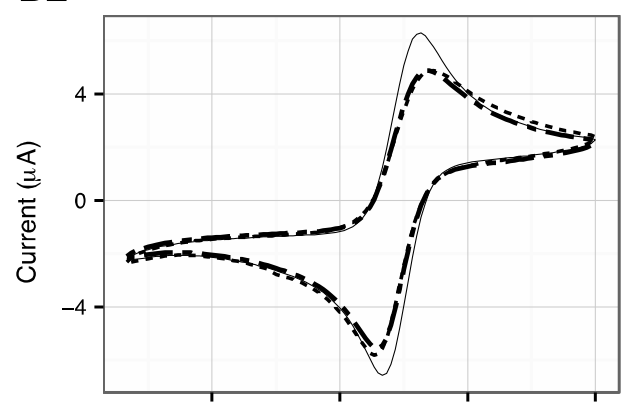

- EDC-NHS - - S Streptavidin - - ETA

B3

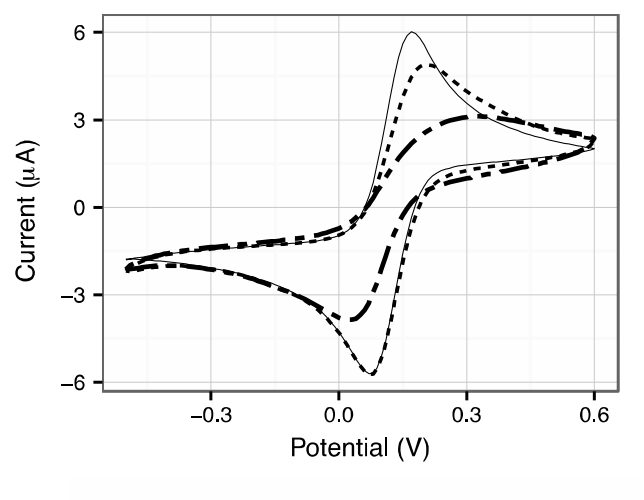

C1

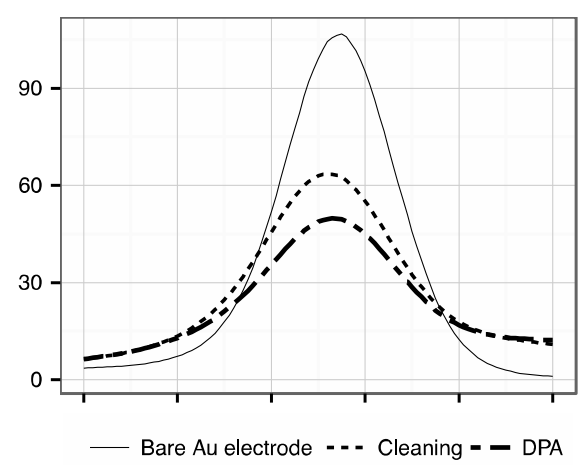

C2

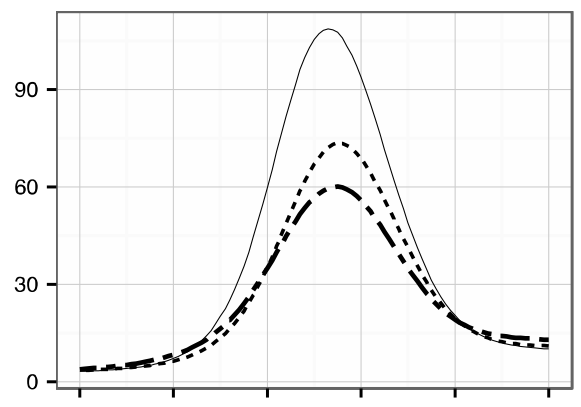

— EDC-NHS - - - Streptavidin - - ETA

C3

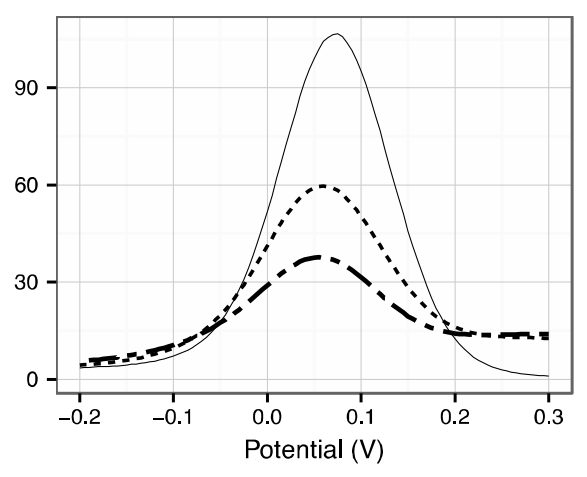

- Bare Au electrode - - - RNA aptamer - - rhOPN

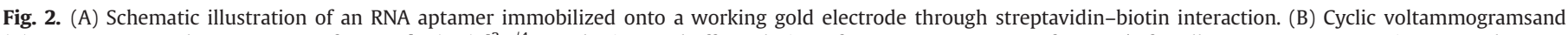

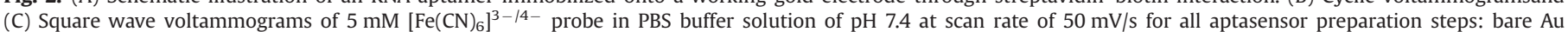
electrode, cleaning, DPA, EDC/NHS, streptavidin, ETA, RNA aptamer and aptamer-rhOPN protein. 
Table 1

Electrochemical parameters obtained after each electrode surface preparation steps.

\begin{tabular}{lccc}
\hline Steps & $\Delta \mathrm{Ep}(\mathrm{mV})$ & Ipa $(\mu \mathrm{A})$ & $\mathrm{Ipc}(\mu \mathrm{A})$ \\
\hline Bare Au electrode & $100 \pm 10$ & $6.9 \pm 0.6$ & $6.9 \pm 0.4$ \\
Cleaning & $175 \pm 8$ & $6.0 \pm 0.2$ & $5.9 \pm 0.3$ \\
DPA & $200 \pm 10$ & $5.68 \pm 0.04$ & $5.38 \pm 0.04$ \\
EDC-NHS & $87 \pm 5$ & $7.4 \pm 0.4$ & $7.6 \pm 0.4$ \\
Strepatvidin & $118 \pm 8$ & $5.8 \pm 0.5$ & $6.4 \pm 0.6$ \\
ETA & $137 \pm 15$ & $5.9 \pm 0.5$ & $6.6 \pm 0.4$ \\
RNA aptamer & $143 \pm 10$ & $5.6 \pm 0.2$ & $6.4 \pm 0.2$ \\
rhOPN & $245 \pm 17$ & $4.14 \pm 0.08$ & $4.8 \pm 0.2$ \\
\hline
\end{tabular}

CV-Cyclic voltammogram; $\Delta$ Ep-potential variation between cathodic and anodic peaks; Ipc-cathodic peak current value; Ipa-anodic peak current value. Mean values \pm standard deviation of three or more replicas are presented.

voltammetry (Fig. 2B) and square wave voltammetry (Fig. 2C). Using the cyclic voltammograms data, electrochemical parameters were calculated namely, the potential variation between cathodic and anodic peaks ( $\Delta \mathrm{Ep}$ ), the cathodic peak current value (Ipc) and anodic peak current value (Ipa), which are given in Table 1 . The results shown are mean values obtained from assays using different SPGEs and prepared in different days.

The first cyclic voltammogram in Fig. 2B1, recorded with the $\left[\mathrm{Fe}(\mathrm{CN})_{6}\right]^{3-14-}$ redox solution, shows the quasi-reversible electrochemical behavior of the gold electrode surface without any treatment, with peaks separation of $100 \mathrm{mV}(\Delta \mathrm{Ep})$ and with similar cathodic and anodic peaks current intensities (Table 1 ). The current response decreased slightly after the cleaning steps with different $\mathrm{H}_{2} \mathrm{SO}_{4}$ solutions, which may be due to achieving a homogeneous surface. After the DPA self-assembled monolayer formation on the electrode surface, an expected decrease of the peaks current intensities was observed, as well as an increase of $\Delta \mathrm{Ep}$, which may be due to the electron transfer blocking. Subsequently, the electrode surface was activated with EDC-NHS (activation of the carboxyl groups), which resulted in an increase of the peaks current intensities (Fig. 2B2) and a decrease in the $\Delta \mathrm{Ep}$ giving a voltammogram close to a reversible behavior. The activated carboxylic groups on the electrode surface facilitate the binding of the streptavidin amine's groups.

The streptavidin layer in the electrode surface increased the $\Delta \mathrm{Ep}$ value and decreased the current peaks intensities, when compared to the previous step. After exposing the working surface electrode to ETA, aiming to block any remaining activated carboxyl groups, the cyclic voltammogram obtained showed an increase in the $\Delta \mathrm{Ep}$ and in the current peaks as compared with the previous one, which may be due to some non-specific blocking of the remaining free carboxylic groups. After the aptamer immobilization on electrode surface, the typical cyclic voltammogram (Fig. 2B3) showed similar $\Delta \mathrm{Ep}$ and lower current peaks comparing to the previous steps. Because of the negative charges of the aptamer backbone phosphate group and $\left[\mathrm{Fe}(\mathrm{CN})_{6}\right]^{3-14-}$ redox probe, the electrostatic repulsive interaction is expected to block the electron transfer (Bang et al., 2005).This experiment clearly demonstrated the effective immobilization of the aptamer onto the working electrode surface. The differences between the cyclic voltammograms obtained after the aptasensor preparation and after its incubation with a standard rhOPN solution $(1540 \mathrm{nM})$ are significant. Indeed, for the rhOPN analysis, the cyclic voltammogram showed the highest potential variation between peaks and the lowest current peaks comparing with all the seven previous steps. The decrease of peak current intensities is an evidence of the aptamer-rhOPN complex formation, by means of the specific recognition increased hindered electron transfer. This signal-off sensing mechanism (negative readout signal) in the current after aptamer-target interaction could be attributed to a change of the aptamer conformation.

SWV was also used for monitoring each biosensor construction step (Fig. 2C). From the visual comparison of the cyclic voltammograms and SWV voltammograms plots (Fig. 2B and C, respectively) it can be concluded that the order of the peak current intensities for all the biosensor's preparation steps is equivalent, showing that both techniques allow monitoring the electrochemical changes occurred during the electrode surface preparation. However, the differences observed in the plots for SWV (of Fig. 2C) are more evident, which was expected considering its higher sensitivity compared to $\mathrm{CV}$. The maximum current intensities of all SWV voltammograms were recorded at a potential range from 0.06 to $0.075 \mathrm{~V}$. As expected, Fig. 2C1 shows that at the bare Au electrode, the redox probe exhibited maximum peak intensity at the potential $0.075 \mathrm{~V}$ and a decrease of $50 \%$ in current intensity after the cleaning step with different $\mathrm{H}_{2} \mathrm{SO}_{4}$ solutions (current intensity maximum at potential $0.060 \mathrm{~V}$ ) and a decrease of $64 \%$ after the DPA immobilization (current intensity maximum at potential $0.065 \mathrm{~V}$ ). After the electrode surface activation with EDC-NHS (Fig. 2C2), the current intensity attained was slightly lower comparing to the result for the bare Au electrode (signal decrease of 7\%). The Fig. 2C2 also showed the current intensity decrease due to the binding of the streptavidin amine's groups in the electrode surface (corresponding to $40 \%$ decrease compared to the bare Au electrode signal) and a shift to a higher potential $(0.075 \mathrm{~V})$. As result of the application of the ETA, to block any remaining activated carboxyl groups, the SWV showed a reduced current intensity peak compared with the previous step, but at the same potential value. In the Fig. $2 \mathrm{C} 3$, it is clear the difference between the surface response of the bare gold electrode after the aptamer immobilization on electrode surface (considering all the described previous steps) and after rhOPN incubation (with a standard solution of $1540 \mathrm{nM}$ ). The current intensity of the voltammograms recorded after the aptamer immobilization decreased 56\% compared with the signal observed for the bare gold surface, with a potential shift to lower value $(0.07 \mathrm{~V})$ and, for after rhOPN analysis incubation an even higher decrease was observed (78\% compared to that of the bare gold surface), showing a potential shift to an even lower potential value $(0.06 \mathrm{~V})$. These last variations, as in $\mathrm{CV}$ results, demonstrate the aptamer-rhOPN complex formation and the existence of a current signal-off sensing mechanism (negative readout signal).

The CV technique was chosen to evaluate the quality control of the aptasensor preparation and to evaluate its analytical performance in the detection of proteins since it allowed obtaining information about the sensor surface's oxidative and reducing process. Overall, these two electrochemical techniques enable monitoring each immobilization step used in construction of the RNA aptamer into the working gold electrode and that aptamer-protein interaction results in a decrease of the current response.

\subsection{Optimization of experimental conditions}

The experimental conditions were optimized in order to obtain an aptasensor with a high sensitivity. Several RNA aptamer concentrations, times and temperatures were evaluated to improve the aptamer immobilization on the working gold modified surface. Also, the incubation time of rhOPN with the aptasensor, was optimized.

For the RNA aptamer concentration studies, several SPGEs aptasensors were prepared with different concentrations of RNA aptamer $(2.5 \mathrm{nM}, 4 \mathrm{nM}, 0.1 \mu \mathrm{M}, 0.5 \mu \mathrm{M}$ and $1 \mu \mathrm{M})$ for $40 \mathrm{~min}$ at room temperature, as described in Section 2.5. Afterwards, each aptasensor was incubated with a rhOPN solution $(1540 \mathrm{nM})$ for one hour at room temperature. Fig. $3 \mathrm{~A}$ shows the current relative change $(\Delta I \%)$ obtained from the redox solution probe $\mathrm{CV}$ after the 
A

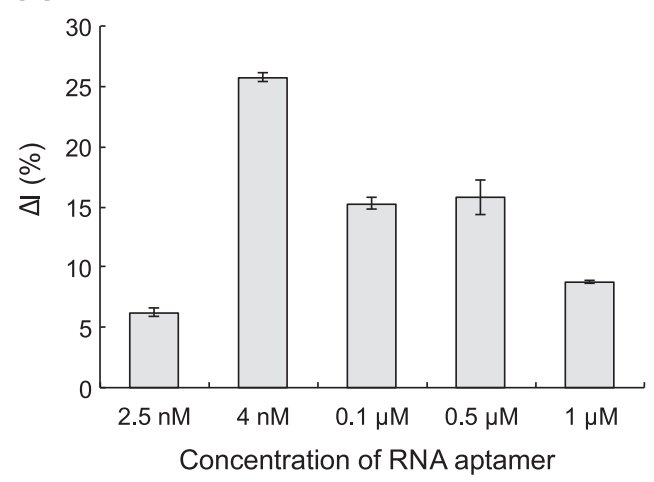

B

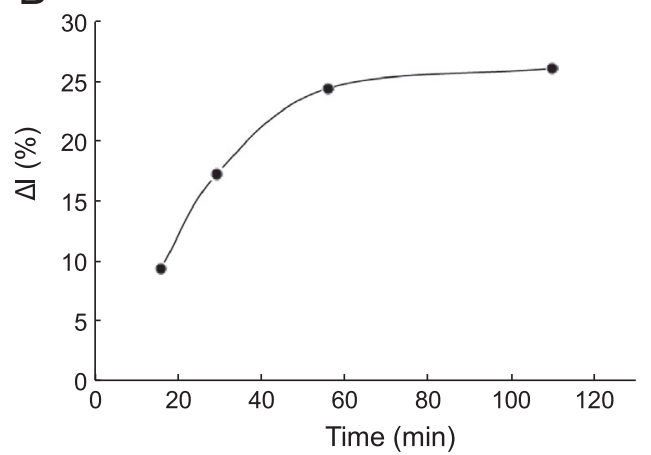

A

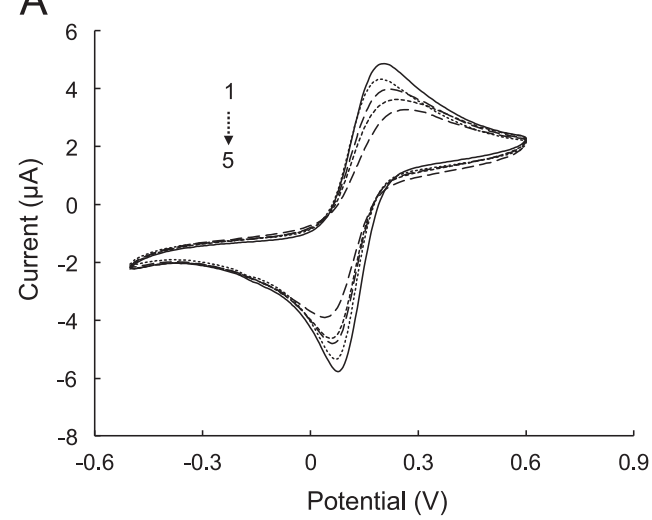

B

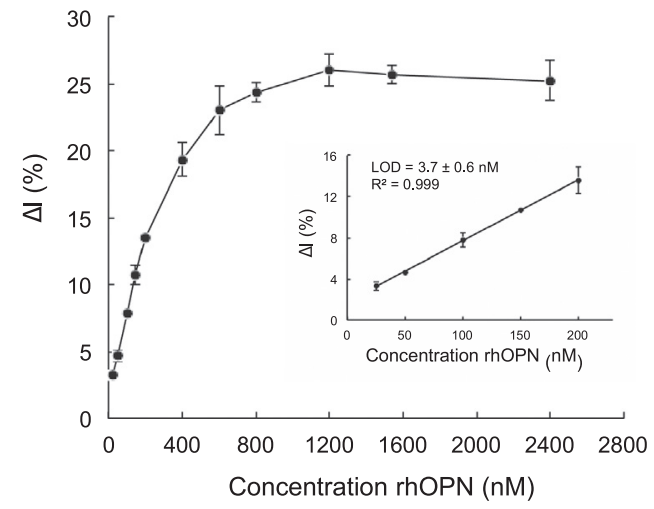

Fig. 3. (A) Optimization of the biotin-RNA aptamer concentration: several concentrations of aptamer have been tested $(2.5 \mathrm{nM}, 4 \mathrm{nM}, 0.1 \mu \mathrm{M}, 0.5 \mu \mathrm{M}$ and $1 \mu \mathrm{M})$. The aptamer concentration has been chosen comparing the relative current signals measured in presence and in absence of rhOPN. Mean values \pm standard deviation of three or more replicas are presented; (B) Effect of the incubation time of the rhOPN solution.

rhOPN incubation step. The results showed that the highest $\Delta I \%$ values were obtained for the aptasensor prepared with an RNA aptamer concentration of $4 \mathrm{nM}$. For concentrations higher than $4 \mathrm{nM}$ there was a decrease in the $\Delta I \%$ values. Therefore, the immobilization with an RNA aptamer concentration of $4 \mathrm{nM}$ was chosen for the following studies since it promoteda greater difference between the signals after immobilization of aptamer and after protein inoculation.The incubation time of the RNA aptamer in the gold working electrode was also evaluated, namely for $40 \mathrm{~min}$ and $2 \mathrm{~h}$ (data not shown). The $\Delta I \%$ values obtained for the two time incubation were also very similar, being the incubation time set equal to $40 \mathrm{~min}$.

Regarding the temperature selection for the immobilization of the aptamer, two temperatures were evaluated, namely $4{ }^{\circ} \mathrm{C}$ and room temperature. The assays were conducted using a $4 \mathrm{nM}$ RNA aptamer solution that was incubated during $40 \mathrm{~min}$ in the SPGEs modified surfaces. The $\Delta I \%$ values obtained from the cyclic voltammograms after incubation of rhOPN (1540 nM) were similar for both temperatures. Thus, all experiments were further carried out at room temperature.

Another important parameter to increase the sensitivity and selectivity of the aptasensor is the incubation time of the target protein. This factor can affect the formation of the aptamer-target complex and therefore must be evaluated. A series of modified electrodes prepared with $4 \mathrm{nM}$ biotin-RNA aptamer were incubated with $1540 \mathrm{nM}$ of rhOPN solution for $15,30,60$ and $120 \mathrm{~min}$ at room temperature. As shown in Fig. 3B, the $\Delta I$ \% values increased gradually with the increase of the incubation time, and it was found to remain almost constant after $60 \mathrm{~min}$ of protein incubation. Thus, an incubation time of $60 \mathrm{~min}$ was chosen as the optimal time for the aptamer-protein complex formation and it

Fig. 4. (A) CV response for rhOPN detection at different concentrations: (1) RNA aptamer immobilized, (2) $100.1 \mathrm{nM}$, (3) $200.2 \mathrm{nM}$, (4) $800.8 \mathrm{nM}$ and (5) $2402.4 \mathrm{nM}$. (B) Electrochemical aptasensor sensitivity analysis of rhOPN using an aptamerimmobilized gold working electrode. Error bars indicate the relative standard deviation of three independent experiments. The insert shows the linear relationship between the $\Delta I(\%)$ and the rhOPN concentrations.

was used in the following experiments.

\subsection{Electrochemical detection of rhOPN}

The performance of the aptasensor was evaluated under the experimental conditions selected, taking into account its response ( $\Delta I \%$ values) to standard solutions containing different concentrations of rhOPN. Each rhOPN determination was carried out using different SPGEs.The cyclic voltammograms of the $\left[\mathrm{Fe}(\mathrm{CN})_{6}\right]^{3-14-}$ solution (redox probe) showed an electrochemical response that could be related to the aptamer surface modification and, in this case, to the amount of aptamer-rhOPN interactions, which is dependent on the rhOPN concentrations. The CV assays showed a decrease in the current response (Ipa and Ipc) as a consequence of the increase of the rhOPN concentration (Fig. 4A). Fig. 4B illustrates the $\Delta I \%$ values as a function of the rhOPN concentration. The results suggest that the increasing values of $\Delta I \%$ are proportional to the increase of the rhOPN concentration, in the rhOPN concentration range between $25 \mathrm{nM}$ and $2402 \mathrm{nM}$, reaching signal saturation near $800 \mathrm{nM}$. A linear correlation could be established for a dynamic concentration range from $25 \mathrm{nM}$ and $200 \mathrm{nM}(\Delta I \%=0.0591( \pm 0.0007) \times[\mathrm{rhOPN}, \mathrm{nM}]+1.81( \pm 0.08)$, Fig. 4B).

The linear correlation coefficient was 0.999 and the calculated detection and quantification limits were $3.7 \pm 0.6 \mathrm{nM}$ and $11 \pm 2 \mathrm{nM}(240 \mathrm{ng} / \mathrm{mL}$ and $715 \mathrm{ng} / \mathrm{mL}$, assuming a molecular weight of $65 \mathrm{kDa}$ ), respectively. This detection limit was quite improved compared to the previous preliminary work of the research group (520 ng/mL) (Meirinho et al., 2014), but higher than 
those previously reported for the detection of human OPN (7.48 ng/ mL (Chen et al., 2014) and 10.7 ng/mL (Cao et al., 2014)), obtained using different measurement techniques, type of electrodes and biosensor preparation methodology. Considering the reported range of plasma OPN concentrations in patients with metastatic breast cancer (up to $290 \mathrm{ng} / \mathrm{mL}$ ) (Bramwell et al., 2014) the proposed aptasensor still could be applied in OPN detection. Also, in the present study, a smaller gold working electrode was used, compared to previous works (Cao et al., 2014; Chen et al., 2014), contributing to the miniaturization of the sensor, as well as the reduction of the amount of reagents and samples' volumes required for the detection.

On the other hand, the future application of other voltammetry techniques, such as square wave voltammetry (SWV) and differential pulse voltammetry (DPV) could increase the sensitivity of the proposed analysis. Indeed, the SWV compared to $\mathrm{CV}$ is a technique that presents broader dynamic range and lower limit of detection. Also, SWV enables a faster analysis with less consumption of electroactive compounds that DPV and consequently reducing blocking problems of the electrode surface (Dogan-Topal et al., 2010). Finally, the use of aptamers as biological recognition elements instead of antibody or antigen (immunological detection) makes the proposed method less expensive and therefore, an interesting commercial alternative. Also, the use of aptamers presents some advantages such as ease and reduced cost of production, as well as the possibility of introducing some chemical modifications to enhance stability, affinity and specificity towards the target. Moreover, aptamers can be immobilized on a large number of transducers surfaces (Balamurugan et al., 2008; Hianik and Wang, 2009; Radi, 2011; Song et al., 2012, 2008; Strehlitz et al., 2008). On other hand, the possible use of new materials or nanoparticles could contribute to reduce the detection limits, since the electrode surface area could be greatly increased and consequently more aptamers could be immobilized, thus contributing to an increase of the sensitivity and specificity.

\subsection{Specificity of aptasensor}

A highly selective response to the target protein over other non-specific proteins is crucial when developing biosensors. Selectivity is a key factor to evaluate the aptasensor performance. The selectivity test was carried out by measuring and comparing the response of the RNA aptamers to rhOPN and to some other non-specific proteins (THR, BSA, LYS and rbOPN), all at a concentration of $200 \mathrm{nM}$. The THR was analyzed as a possible interferent because it is a secreted serine protease found in the blood (Beausoleil et al., 2011). The other proteins, though not present in human body fluids were also analyzed. The rbOPN was analyzed because it exhibits a cDNA sequence with high degree of homology with that of rhOPN (Wai and Kuo, 2004). The BSA and LYS were used to analyze if the effect of the proteins molecular weight could affect the detection. For each individual protein determination, different SPGE were used. Fig. 5 illustrates the $\Delta I \%$ obtained for rhOPN and also for the non-specific proteins tested. The results showed that the RNA aptamer had a good sensitivity to rhOPN when compared with the proteins BSA, LYS and rbOPN. However, their $\Delta I \%$ values cannot be neglected and a more pronounced response was observed in the presence of THR. Aptamers are described as small single-stranded RNA or DNA with high affinity and specificity for a given target molecule. However, some aptamers can also bind to other molecules presenting similar structures without losing their specificity (Lakhin et al., 2013). The possible aptamer cross-reactivity may explain the results obtained for THR. The rhOPN and THR structures are not similar. Nonetheless, the rhOPN contains several conserved domains including THR cleavage domain RSK site, leading to the breakdown of the protein into

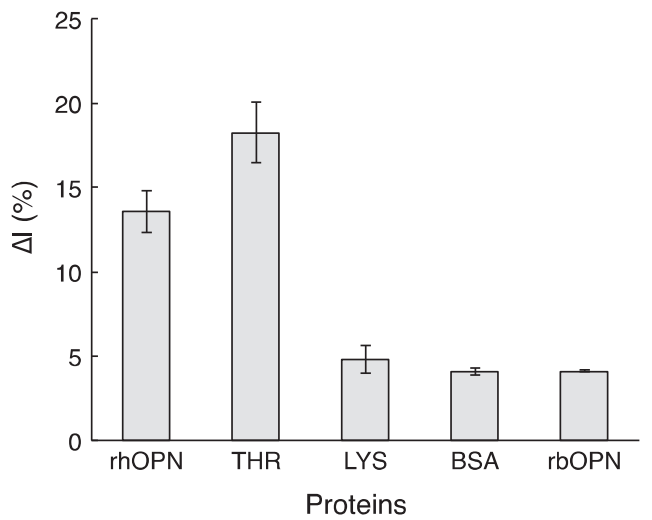

Fig. 5. Bar chart of $\mathrm{CV}$ response $(\Delta I \%)$ to non-specific proteins $(200 \mathrm{nM})$ : BSA bovine serum albumin, LYS - lysozyme, rbOPN - bovine osteopontin and THR thrombin and for specific-protein rhOPN - human osteopontin. Error bars indicate the relative standard deviation of three independent experiments.

two fragments (Beausoleil et al., 2011; Sivakumar and Niranjali Devaraj, 2014). Thus, during the process of RNA aptamer selection, the cleavage of OPN might have occurred, and therefore the RNA aptamer could hold a site that is able to recognize THR. The results obtained suggest that the RNA aptamer used in this work may have two recognition sites, one for rhOPN and another for THR.

To assess the possible RNA aptamer binding affinity towards THR, fluorescence assays were also performed using the same procedure described in Section 2.3 (experimental conditions) and Section 2.4 (mathematical procedure). For FAM-RNA aptamer-THR complex formation, a $K_{d}$ value of $1.3 \mathrm{nM}$ was obtained for $4 \mathrm{~h}$ of incubation. This result suggests that the RNA aptamer may have a binding site for THR, with a higher affinity than that observed for rhOPN $\left(K_{d, \text { THR }}<K_{d, \text { rhOPN }}\right)$

\subsection{Reproducibility and stability of the aptasensor}

To evaluate the reproducibility of the aptasensor, four different SPGEs were prepared in the same day, under the same conditions and tested using a solution with a concentration of $1540 \mathrm{nM}$ of rhOPN. Also, seven other SPGEs were prepared in different days and tested with $200 \mathrm{nM}$ rhOPN. The current response obtained from the aptasensors prepared in the same and different days showed a relative standard deviation (RSD \%) of $4.2 \%$ and $5.7 \%$, respectively, thus suggesting that the aptasensor preparation method was reproducible and precise. The overall experimental results indicate that the aptasensor used in this work had a good reproducibility (RSD \% less than $6 \%$ ).

The aptasensor stability was also evaluated since this is another important parameter for the practical application of a sensor. To evaluate this parameter, the RNA aptamer half-life was studied. Our results were compared with the ones reported by Mi et al (2009b) and Talbot et al. (2011), that reported half-lives of $8 \mathrm{~h}$ and more than $24 \mathrm{~h}$ for in vitro assays and human serum, respectively (Mi et al., 2009b; Talbot et al., 2011). The aptasensor stability was evaluated by comparing the $\Delta I \%$ of three SPGEs, prepared under the same experimental conditions, and stored during $2,4,6,8 \mathrm{~h}$ and 10 days. When compared with the initial $\Delta I \%$ value, the response after $8 \mathrm{~h}$ and 10 days, was still 95\% and 88\%, respectively, showing a satisfactory stability of the aptasensor response along time. This result may explain the difficulty in regenerating the aptamer, even when using different regeneration solutions (e.g. $2 \mathrm{M}$ of $\mathrm{NaCl}$ or $7 \mathrm{M}$ of urea). 


\section{Conclusion}

This work represents a proof-of-principle that the proposed electrochemical aptasensor is a simple and sensitive tool with satisfactory performance, reproducibility and stability for the detection of rhOPN. However, the developed aptasensor is not fully specific for the target protein when other interfering species are present. Therefore, further studies are required, namely in the selection of new and more specific aptamers against rhOPN, in order to improve its detection performance and selectivity, as well as the implementation of other voltammetric techniques such as square wave voltammetry (SWV) and differential pulse voltammetry (DPV), which are also used in the development of aptasensors.

\section{Conflicts of Interest}

The authors declare no conflict of interest.

\section{Acknowledgments}

This work was funded by Fundação para a Ciência e a Tecnologia (FCT) through the PhD grant SRFH/ BD/65021/2009. Moreover, the work was co-financed by FCT and FEDER under Program PT2020 (Project UID/EQU/50020/2013); by the Strategic Project PEst-OE/EQB/LA0023/2013 and by the project ref. RECI/BBB-EBI/ 0179/2012 (project number FCOMP-01-0124-FEDER-027462) funded by FCT.

\section{References}

Ahmed, M., Kundu, G.C., 2010. Mol. Cancer 9, 1113-1126.

Anborgh, P.H., Mutrie, J.C., Tuck, A.B., Chambers, A.F., 2011. J. Cell Commun. Signal. 5, 111-122.

Arshak, K., Velusamy, V., Korostynska, O., Oliwa-Stasiak, K., Adley, C., 2009. IEEE Sens. J. 9, 1942-1951.

Bache, M., Kappler, M., Wichmann, H., Rot, S., Hahnel, A., Greither, T., Said, H.M., Kotzsch, M., Würl, P., Taubert, H., Vordermark, D., 2010. BMC Cancer 10 132-148.

Balamurugan, S., Obubuafo, A., Soper, S. a, Spivak, D.A., 2008. Anal. Bioanal. Chem. 390, 1009-1021.

Bang, G.S., Cho, S., Kim, B., 2005. Biosens. Bioelectron. 21, 863-870.

Beausoleil, M.S., Schulze, E.B., Goodale, D., Postenka, C.O., Allan, A.L., 2011. BMC Cancer 11, 25-37.

Bloomfield, V.A., 2014. Using R for Numerical Analysis in Science and Engineering. Chapman \& Hall/CRC.

Bramwell, V.H.C., Doig, G.S., Tuck, A.B., Wilson, S.M., Tonkin, K.S., Perera, F., Vandenberg, T.A., Chambers, A.F., 2006. Clin. Cancer Res. 12, 3337-3343.

Bramwell, V.H.C., Tuck, A.B., Chapman, J.-A.W., Anborgh, P.H., Postenka, C.O., AlKatib, W., Shepherd, L.E., Han, L., Wilson, C.F., Pritchard, K.I., Pollak, M.N., Chambers, A.F., 2014. Breast Cancer Res. 16, R8.

Cao, Y., Chen, D., Chen, W., Yu, J., Chen, Z., Li, G., 2014. Anal. Chim. Acta 812, 45-54.
Centi, S., Sanmartin, B., Tombelli, S., Palchetti, I., 2009. Electroanalysis 21 1309-1315.

Chen, H., Mei, Q., Jia, S., Koh, K., Wang, K., Liu, X., 2014. Analyst 139, 4476-4481.

Dogan-Topal, B., Ozkan, S.A., Uslu, B., 2010. Open Chem. Biomed. Methods J. 3, $56-73$.

Ermer, J., Miller, J., 2005. Wiley: New York. Wiley-VCH GmbH and co. KGaA. Weinheim, ISBN: 3-527-31255-2.

Farghaly, O. a, Hameed, R.S.A., 2014. Int. J. Electrochem. Sci. 9, 3287-3318.

Ferlay, J., Soerjomataram, I., Ervik, M., Dikshit, R., Eser, S., Mathers, C., Rebelo, M. Parkin, D.M., Forman, D., Bray, F., 2013. GLOBOCAN 2012 v1.0, Cancer Incidence and Mortality Worldwide: IARC CancerBase. No. 11.

Hianik, T., Wang, J., 2009. Electroanalysis 21, 1223-1235.

Jing, M., Brwser, M.T., Browser, M.T., 2011. Anal. Chim. Acta 686, 9-18.

Kim, Y.-J., Kim, Y.S., Niazi, J.H., Gu, M.B., 2010. Bioprocess Biosyst. Eng. 33, 31-38.

Lai, R.Y.R.Y., Plaxco, K.W.K.W., Heeger, A.J.A.J., 2007. Anal. Chem. 79, 229-233.

Lakhin, A.V., Tarantul, V.Z., Gening, L.V., 2013. Acta Nat. 5, 34-43.

Macrì, A., Versaci, A., Lupo, G., Trimarchi, G., Tomasello, C., Loddo, S., Sfuncia, G., Caminiti, R., Teti, D., Famulari, C., 2009. Tumori 95, 48-52.

Meirinho, S.G., Dias, L.G., Peres, A.M., Rodrigues, L.R., 2014. Procedia Eng. 87, 316-319.

Mi, Z., Guo, H., Kuo, P.C., 2009a. BMC Res. Notes 2, 119-127.

Mi, Z., Guo, H., Russell, M.B., Liu, Y., Sullenger, B. a, Kuo, P.C., 2009b. Mol. Ther. 17, $153-161$.

Mirza, M., Shaughnessy, E., Hurley, J.K., Vanpatten, K.A., Pestano, G. a, He, B., Weber, G.F., 2008. Int. J. Cancer 122, 889-897.

Olowu, R.A., Ndangili, P.M., Baleg, A.A., Ikpo, C.O., Njomo, N., Baker, P., Iwuoha, E., 2011. Int. J. Electrochem. Sci. 6, 1686-1708.

Potty, A.S.R., Kourentzi, K., Fang, H., Jackson, G.W., Zhang, X., Legge, G.B., Willson, R. C., 2009. Biopolymers 91, 145-156.

Radi, A.-E., 2011. Int. J. Electrochem. 2011, 1-17.

Rodrigues, L.R., Lopes, N., Sousa, B., Vieira, D., Milanezi, F., 2009. Open Breast Cancer J. 1, 1-9.

Rodrigues, L.R., Teixeira, J.A., Schmitt, F.L., Paulsson, M., Lindmark-Mansson, H., 2007. Biomark. Prev, 16, 1087-1097.

Rudland, P.S., Platt-Higgins, A., El-Tanani, M., De Silva Rudland, S., Barraclough, R., Winstanley, J.H.R., Howitt, R., West, C.R., 2002. Cancer Res. 62, 3417-3427.

Saberian, M., Hamzeiy, H., Aghanejad, A., Asgari, D., 2011. Bioimpacts 1, 31-37.

Sivakumar, S., Niranjali Devaraj, S., 2014. J. Diabetes Metab. Disord. 13, 1-14.

Song, K.-M., Lee, S., Ban, C., 2012. Sensors, 12. Basel, pp. 612-631.

Song, S., Wang, L., Li, J., Zhao, J., Fan, C., 2008. Anal. Chem. 27, 108-117.

Strehlitz, B., Nikolaus, N., Stoltenburg, R., 2008. Sensors 8, 4296-4307.

Talbot, L.J., Mi, Z., Bhattacharya, S.D., Kim, V., Guo, H., Kuo, P.C., 2011. Surgery 150, 224-230.

Thorat, D., Sahu, A., Behera, R., Lohite, K., Deshmukh, S., Mane, A., Karnik, S., Doke, S., Kundu, G.C., 2013. Oncol. Lett. 6, 1559-1564.

Timur V. Minpack. Im: R interface to the Levenberg-Marquardt nonlinear leastsquares algorithm found in MINPACK, plus support for bounds Elzhov, Katharine M. Mullen, A.-N.S. and Ben, Bolker 1201317.

Tran, D.T., Janssen, K.P.F., Pollet, J., Lammertyn, E., Anné, J., Van Schepdael, A., Lammertyn, J., 2010. Molecules 15 1127-40.

Tuck, A.B., Chambers, A.F., Allan, A.L., 2007. J. Cell. Biochem. 868, 859-868.

Velasco-Garcia, M.N., Missailidis, S., 2009. Gene Ther. Mol. Biol. 13, 1-9.

Velusamy, V., Arshak, K., Korostynska, O., Oliwa, K., Adley, C., 2010. Biotechnol. Adv. 28, 232-254.

Wai, P., Kuo, P., 2004. J. Surg. Res. 241, 228-241.

Wai, P., Kuo, P., 2008. Cancer Metastasis 27, 103-118.

Weber, G.F., Lett, G.S., Haubein, N.C., 2010. Br. J. Cancer 103, 861-869.

Weber, G.F., Lett, G.S., Haubein, N.C., 2011. Oncol. Rep. 25, 433-441.

Xiao, Y., Lubin, A.A., Heeger, A.J., Plaxco, K.W., 2005a. Angew. Chem. 44, 5456-5459.

Xiao, Y., Piorek, B.D., Plaxco, K.W., Heeger, A.J., 2005b. J. Am. Chem. Soc. 127, 17990-17991.

Xu, Y., Cheng, G., He, P., Fang, Y., 2009. Electroanalysis 21, 1251-1259.

Yu, T., Li, J., Liu, Q., Cheng, W., Zhang, D., Ju, H., 2012. Int. J. Electrochem. Sci. 7, 8533-8542. 